volume of blood transfused was 56 (range 20-105) $\mathrm{ml}$. Donor blood showed very small concentrations $(0-2 \mathrm{pmol} / \mathrm{l})$.

\section{Comment}

These preliminary results show that atrial natriuretic peptide circulates in the fetus and placenta. The higher fetal than maternal concentrations and the values in the three intracardiac samples are consistent with production by the fetus.

The higher fetal concentrations in the isoimmunised group may reflect expansion of the fetoplacental plasma volume, which suggests that release of the peptide in fetuses is regulated in the same way as that in adults. The dynamic response to intravascular transfusion in this series (despite the dilutional effect of the donor blood) is supported by experimental work ${ }^{3}$ and indicates that intravascular volume expansion is an important stimulus for release of the peptide.

Atrial natriuretic peptide may influence umbilical blood flow as specific receptors have been identified in the placenta. ${ }^{4}$ An additional role might be to regulate the volume of amniotic fluid, as in sheep fetal production of urine increases in response to atrial natriuretic peptide.

1 Laragh JH. Atrial natriuretic hormone, the renin-aldosterone axis and blood pressure electrolyte homeostasis. N Engl f Med 1987;313:1330-40.

2 Richards AM, Tonolo G, McIntyre GD, et al. Radio-immunoassay for plasma atrial natriuretic peptide: a comparison of direct and pre-extracted methods. f Hypertension 1987;5:227-36.

3 Ross MG, Ervin MG, Lam RW, et al. Plasma atrial natriuretic peptide response to volume expansion in the ovine fetus. Am J Obstet Gynecol 1987;157:1292-7. Hatjis CJ, Grogan DM. Atrial natriuretic peptide receptors in normal human placentas. Am f Obstet Gynecol 1988;159:587-91.

5 Brace RA, Cheung CY. Cardiovascular and fluid responses to atrial natriuretic factor in sheep fetus. Am 7 Physiol 1987:253:R561-7.

(Accepted 24 January 1989)

\title{
Morphine and dryness of the mouth
}

\section{D White, P J Hoskin, G W Hanks, J M Bliss}

Continuing Care Unit, Royal Marsden Hospital, London SW3 6JJ I D White, RGN, research sister

P J Hoskin, FRCR, research fellow

G W Hanks, MRCP, consultant physician

Section of Epidemiology, Institute of Cancer Research, Sutton, Surrey SM2 5NG

J M Bliss, MSC, statistician

Correspondence to: Dr Hanks.

BrMed f 1989;298:1222-3
Morphine sulphate taken by mouth is the drug of choice when a strong opioid analgesic is required to control pain caused by cancer.' Specific gastrointestinal side effects such as nausea, vomiting, reduced gastrointestinal motility, and reduced biliary and pancreatic secretions are well documented. Dryness of the mouth is not generally recognised as a side effect of morphine, ${ }^{23}$ but clinical experience suggests that it is a common complaint of patients with cancer who are receiving it. We studied the prevalence of dryness of the mouth in patients with cancer to see whether it is associated with the use of morphine.

\section{Patients, methods, and results}

All patients admitted to this hospital during a period of eight weeks were entered into the study except those who had other reasons for having a dry mouthnamely, those receiving radiotherapy or surgery to the head and neck, those who had received a general anaesthetic within the previous 48 hours, those whose intake by mouth was restricted, and those receiving cytotoxic chemotherapy.

We recorded demographic data; details of the current analgesic being taken (drug, dose, preparation, and duration of treatment at the current dose) and of other drug treatment; whether dentures were worn; and whether there was evidence of oral candidiasis. Patients completed a questionnaire comprising two four point categorical scales (Do you suffer from a dry mouth? How dry has it been in the past 24 hours?) and a $10 \mathrm{~cm}$ visual analogue scale, which also measured the severity of the dryness during the preceding 24 hours and was included to support the results from the second categorical scale.

A high degree of concordance was found between the categorical and visual analogue scales (Goodman and Kruskal's gamma statistic $=0.97)$. The results were based on the answers to the question for the second categorical scale.

Data were obtained from 199 patients, all but 10 of whom had malignant disease. Forty eight men aged 22 84 (median 63) and 151 women aged 22-88 (median 60) completed the questionnaire.

Opioid analgesics were being taken by 131 patients, of whom 67 were taking morphine. Of those taking morphine, 45 received it as an aqueous solution, 18 as controlled release tablets, and two as suppositories; two patients received parenteral diamorphine. Dryness of the mouth at some time during treatment was reported by 113 of the 199 patients, of whom 42 had a dry mouth most or all of the time. No significant association was observed between the severity of the dryness of the mouth and sex, age, primary diagnosis, reason for admission, wearing dentures, candidiasis of the mouth, or smoking.

Drugs other than analgesics were being taken by 156 of the 199 patients, and 72 of them took drugs that were known to cause a dry mouth - for example, those with anticholinergic activity and diuretics. As expected, a significant association was found between taking these drugs and the severity of the dryness of the mouth (test for trend $\chi^{2}=9 \cdot 31, \mathrm{df}=1, \mathrm{p}=0 \cdot 002$ ). Further analysis was therefore undertaken with the type of analgesic drug stratified according to whether patients were also taking drugs known to cause dryness of the mouth.

Assessment of dryness of mouth during previous 24 hours in 199 patients according to type of analgesic drug and concurrent treatment given. Values are numbers (percentages) of patients

\begin{tabular}{|c|c|c|c|c|}
\hline \multirow[b]{2}{*}{ Analgesic group } & \multicolumn{4}{|c|}{ Dryness of mouth (categorical scale) } \\
\hline & Normal & $\begin{array}{l}\text { Slightly } \\
\text { dry }\end{array}$ & $\begin{array}{c}\text { Moderately } \\
\text { dry }\end{array}$ & $\begin{array}{c}\text { Extremely } \\
\text { dry }\end{array}$ \\
\hline \multicolumn{5}{|c|}{ Concomitant treatment expected to cause dry mouth } \\
\hline \multirow{2}{*}{$\begin{array}{l}\text { Morphine }(n=35) \\
\text { Non-opioid, weak opioid, or } \\
\text { no analgesics }(n=37)\end{array}$} & $10(29)$ & $3(9)$ & $9(26)$ & $13(37)$ \\
\hline & $18(49)$ & $6(16)$ & $7(19)$ & $6(16)$ \\
\hline \multicolumn{5}{|c|}{ No concomitant treatment or treatment not expected to cause dry mouth } \\
\hline \multirow{2}{*}{$\begin{array}{l}\text { Morphine }(n=32) \\
\text { Non-opioid, weak opioid, or } \\
\text { no analgesics }(n=95)\end{array}$} & $8(25)$ & $5(16)$ & $14(44)$ & $5(16)$ \\
\hline & $61(64)$ & $11(12)$ & $21(22)$ & $2(2)$ \\
\hline
\end{tabular}

The table shows the results. A highly significant association was found between the use of morphine and dryness of the mouth (test for trend (stratified) $\chi^{2}=$ $20.62, \mathrm{df}=1, \mathrm{p}<0.0005)$. When concurrent treatment was allowed for patients receiving morphine were roughly four times more likely to have a dry mouth of any severity than patients taking weak opioid, non-opioid, or no analgesics $(95 \%$ confidence interval for odds ratio $2 \cdot 0$ to $7 \cdot 2$ by logistic regression analysis ${ }^{4}$ ).

\section{Comment}

Our results show a clear association between the use of morphine and dryness of the mouth in this sample of patients. The mechanism for this effect is unclear. We 
recommend recognition of this side effect so that careful attention can be paid to oral comfort and hygiene.

The Institute of Cancer Research receives financial support from the Cancer Research Campaign and the Medical Research Council. PJH is supported by the Cancer Research Campaign. We thank Felicity Fleetwood for typing the manuscript.
1 Hanks GW, Hoskin PJ. Opioid analgesics in the management of pain in patients with cancer. A review. Palliative Medicine 1987;1:1-25.

2 Duthie JR, Nimmo WS. Adverse effects of opioid analgesic drugs. Br $\mathcal{F}$ Anaesth 1987;59:61-77.

3 Jaffe JH, Martin WR. Opioid analgesics and antagonists. In: Gilman AG, Goodman LS, Rall TW, Murad F, eds. The pharmacological basis of therapeutics. 7th ed. New York: Macmillan, 1985:498.

4 McCullagh P, Nelder JA. Generalized linear models. London: Chapman and Hall, 1983.

5 Cheater F. Xerostomia in malignant disease. Nursing Mirror 1985; July 17:25-7.

(Accepted 27 February 1989)

\section{Relief care and risk of death in psychogeriatric patients}

\author{
Carolyn Selley, Michael Campbell
}

\begin{abstract}
Psychogeriatric Unit, Moorgreen Hospital, Southampton SO3 3JB Carolyn Selley, MRCPSYCH,
\end{abstract} senior registrar

\section{Department of Medical Statistics and Computing, University of \\ Southampton, \\ Southampton \\ Michael Campbell, PHD, senior lecturer}

Correspondence to: $\operatorname{Dr} C$ Selley, Department of Psychotherapy, Department of Psychiatry, Royal South

Hants Hospital, Southampton SO9 4PE.

Br Med f 1989;298:1223 parisons of mortality are difficult. the time spent in each place.
In a paper on the hazards for elderly people of a single admission for respite and social care Rai et al described a high mortality of $22 \%$. This compared poorly with the mortality for patients admitted with acute illness to geriatric wards, and they concluded that such admissions for relief should be discouraged. ${ }^{1}$ Their paper led to critical correspondence and understandable concern to carers of elderly, chronically sick patients. ${ }^{2} \mathrm{~A}$ major problem in interpreting this paper is that the admission policy in different centres and for different illnesses probably varies, and so direct com-

Relief admissions are widely used in the psychogeriatric unit at this hospital. We studied whether there was an increased risk of a patient dying when admitted to the unit for relief care compared with the risk for that patient at home or elsewhere, allowing for

\section{Methods and results}

We studied case notes of patients aged over 65 admitted to the relicf admission programme from 6 February 1985 to 5 February 1988 who died in that period. A relief admission was defined as an admission arranged solely to allow the carer respite. An admission where the notes indicated physical or psychiatric deterioration as the cause was excluded. Patients were regarded as being on the relief admission programme from when they were first admitted in the period studied. Patients were withdrawn from the programme if they were admitted to long stay hospital care or a residential home. Details of sex, age, and the total number of relief admissions of each patient were obtained. Any physical disability recorded in the notes that was likely to increase the care the patient required or to be a risk to future health was noted.

We obtained the numbers of patients dying during and outside relief admissions during their time on the programme. A death during relief admission was defined as a death occurring while the patient was in hospital or directly occurring because of a condition contracted during relief admission. We calculated the number of days each patient spent in hospital during relief care and the number of days on which they did not receive relief care during the programme. We analysed the differences in mortality for those dying during and outside relief admissions with the Mantel-
Haenszel test and calculated $95 \%$ confidence intervals with Miettinen's test based approximation. ${ }^{3}$

During the three years 48 out of 210 patients died while still on the relief admission programme. They had been admitted for relief care on 218 occasions. All but one set of case notes were traced, and sufficient information was obtained from nurses' notes for this patient to be included. The table shows the results. Taking into account the amount of time that patients did and did not receive relief care, the differences between the observed and expected numbers of deaths were not significant $\left(\chi^{2}=0 \cdot 19, \mathrm{df}=1, \mathrm{p}>0 \cdot 5\right)$. The relative risk of dying during relief care was $1 \cdot 14(95 \%$ confidence interval 0.64 to $2 \cdot 02$ ).

Characteristics of deaths in three years of relief admission programme

\begin{tabular}{lcc}
\hline & $\begin{array}{c}\text { Deaths during } \\
\text { relief care }\end{array}$ & $\begin{array}{c}\text { Deaths not during } \\
\text { relief care }\end{array}$ \\
\hline No of deaths & 19 & 29 \\
Expected No of deaths & $17 \cdot 53$ & $29 \cdot 47$ \\
Sex ratio (men:women) & $1: 2 \cdot 2$ & $1: 0 \cdot 62$ \\
Mean (range) age (years) & $81(65-92)$ & $78(67-89)$ \\
\% With physical disability & 80 & 80 \\
Average total No of relief & $6 \cdot 2$ & $3 \cdot 4$ \\
admissions/person & & \\
\hline
\end{tabular}

^Based on time for which each patient did and did not receive relief care.

\section{Comment}

In terms of mortality alone it remains uncertain whether a single relief admission carries a risk or an advantage. We did not find a significant increase in the risk of death during relief care, but we established the range of relative risk. The exclusion of admissions precipitated by deterioration and the comparison of each subject with himself or herself in the analysis may account for the contrast with Rai et al's work. In addition, our patients may have differed biologically from those patients admitted for respite care to geriatric medical wards. Taken with the clear benefits of this programme described elsewhere ${ }^{4}$ our results support the continued use of relief admissions in this type of service.

We thank Dr C Godber, Dr H Rosenvinge, and Dr D Wilkinson of the Southampton psychogeriatric service, who gave their support and contributed to the work; and Mrs B Humphries for secretarial help.

1 Rai GS, Bielawska C, Murphy P, Wright G. Hazards for elderly people admitted for respite and social care. $\mathrm{Br} \mathrm{Med} \mathcal{f}$ 1986;292:240.

2 Gill $M$. Correspondence on hazards for elderly people admitted for respite and social care. Br Med f 1986;292:482.

Armitage P, Berry G. Statistical methods in medical research. Oxford: Blackwell Scientific Publications, 1987.

4 Pearson N. An assessment of relief hospital admissions for elderly patients with dementia. Health Trends 1988;20:120-1.

(Accepted 23 February 1989) 